\title{
Amperometric Phenol Biosensor Based on a New Immobilization Matrix: Polypyrrole Nanotubes Derived from Methyl Orange as Dopant
}

\author{
Huiqin Li, Xin Hu, Hongmei Zhu, Yang Zang, Huaiguo Xue* \\ College of Chemistry and Chemical Engineering, Yangzhou University, Yangzhou, 225002, Jiangsu, \\ P. R. China. \\ *E-mail address: chhgxue@yzu.edu.cn
}

doi: $10.20964 / 2017.07 .80$

Received: 19 April 2017 / Accepted: 14 May 2017 / Published: 12 June 2017

\begin{abstract}
A novel polypyrrole nanotubes (PPy-NTs) derived from methyl orange (MO) was used as matrix to construct a highly responsive phenol biosensor. The phenol sensor based on polyphenol oxidase could be easily obtained by casting the bio-composite via the cross-linking in the presence of glutaraldehyde on glassy carbon electrode surface. PPy-NTs matrix has features of special three-dimensional structure, biocompatible properties and high surface area, and the features above resulted in high enzyme immobilization and the enzyme buried in PPy-NTs retained its activity to a large extent. This biosensor exhibited a series of better performance such as high sensitivity $\left(2981 \mathrm{~mA} \cdot \mathrm{M}^{-1} \cdot \mathrm{cm}^{-2}\right)$, good affinity to its substrate (the apparent Michaelis-Menten constant was $0.12 \mathrm{mM}$ ) and remarkable longterm stability (it retained $88 \%$ of the original activity after 30 days) and acceptable repeatability. The detection limit of the biosensor was $1.22 \mathrm{nM}$. Furthermore, the optimization of biosensor preparation and effects of experimental variables, such as $\mathrm{pH}$, temperature and potential of the sensor were discussed.
\end{abstract}

Keywords: Electrochemical biosensor; Polypyrrole nanotubes; Phenols

\section{$\underline{\text { FULL TEXT }}$}

(C) 2017 The Authors. Published by ESG (www.electrochemsci.org). This article is an open access article distributed under the terms and conditions of the Creative Commons Attribution license (http://creativecommons.org/licenses/by/4.0/). 